\title{
Malignant Essential Hypertension
}

National Cancer Institute

\section{Source}

National Cancer Institute. Malignant Essential Hypertension. NCI Thesaurus. Code C34802.

Essential hypertension with rapid progression to severe high blood pressure, papilledema, and renal failure. 